\title{
The Value of $\$ 600$ Across States Hit Hardest by COVID-19
}

YiLi Chien, Research Officer and Economist

Julie Bennett, Research Associate

ongress recently passed the CARES Act to provide economic relief in response to the ongoing COVID-19 pandemic. Among many other policies, CARES provides an extra $\$ 600$ per week in unemployment benefits to all eligible unemployment insurance (UI) claimants until July 31, 2020. This $\$ 600$ supplement is uniform across all states. However, the purchasing power of $\$ 600$ varies substantially across states hit hardest by the pandemic, raising the question of whether the equal distribution of $\$ 600$ across states is an equitable distribution.

We examine differences in the purchasing power of $\$ 600$ across U.S. states using regional price parities (RPPs) from the Bureau of Economic Analysis (BEA). ${ }^{1}$ Adjusting for regional price differences, the additional $\$ 600$ UI benefit is worth the most in Mississippi (\$700) and the least in
Hawaii (\$506). The figure shows the differing value of $\$ 600$ across the United States.

The table displays the purchasing power of $\$ 600$ in states that have been hit hardest by the COVID-19 pandemic, from both a public health and an economic perspective. The first (left-hand) section reports states hardest hit in terms of confirmed COVID-19 cases in the state, ${ }^{2}$ and the second (right-hand) section reports states hardest hit in terms of total initial unemployment claims from the week ending March 21, 2020, to the week ending April 18, 2020. ${ }^{3}$

New York, New Jersey, California, Massachusetts, and Connecticut are all states where $\$ 600$ has relatively lower purchasing power and where COVID-19 has had the largest impact, from a public health and/or economic perspective. Meanwhile, other states severely hit by the pandemic reap

Value of $\$ 600$ Across States

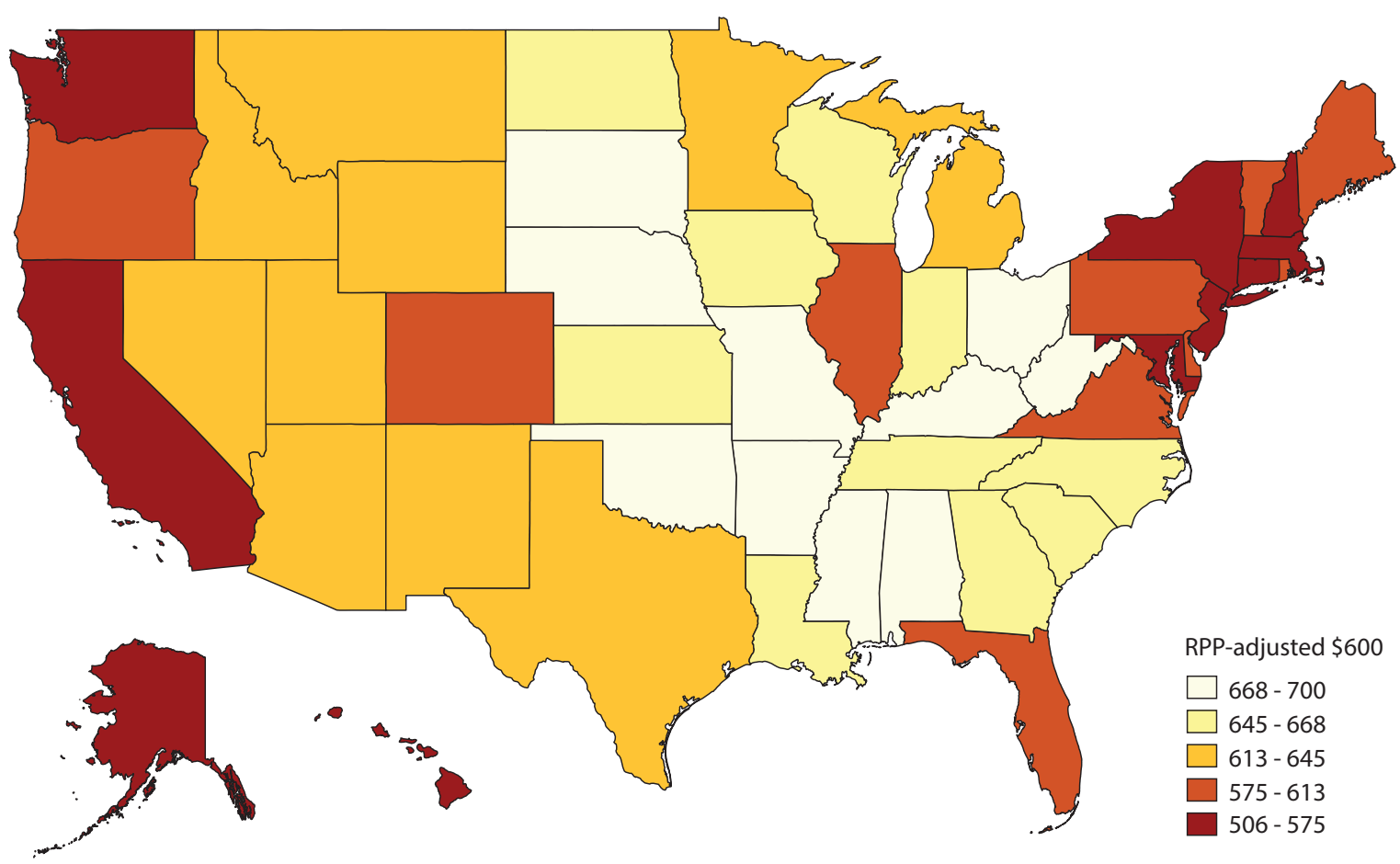

SOURCE: BEA and authors' calculations. 


\section{Purchasing Power of $\$ 600$ Across States Most Affected by the COVID-19 Pandemic}

\begin{tabular}{|c|c|c|c|c|c|}
\hline \multicolumn{2}{|c|}{$\begin{array}{l}\text { States hardest hit by COVID-19 } \\
\text { (COVID-19 cases) }\end{array}$} & \multirow{2}{*}{$\begin{array}{c}\text { Purchasing power } \\
\text { of } \$ 600\end{array}$} & \multicolumn{2}{|c|}{$\begin{array}{l}\text { States hardest hit by COVID-19 } \\
\text { (unemployment) }\end{array}$} & \multirow{2}{*}{$\begin{array}{c}\text { Purchasing power } \\
\text { of } \$ 600 \\
\$ 523\end{array}$} \\
\hline 1. New York & 271,145 & & 1. California & $3,352,512$ & \\
\hline 2. New Jersey & 95,914 & $\$ 531$ & 2. Pennsylvania & $1,492,717$ & $\$ 613$ \\
\hline 3. Massachusetts & 42,944 & $\$ 556$ & 3. New York & $1,390,462$ & $\$ 518$ \\
\hline 4. California & 39,010 & $\$ 523$ & 4. Texas & $1,301,441$ & $\$ 619$ \\
\hline 5. Pennsylvania & 38,255 & $\$ 613$ & 5. Michigan & $1,177,221$ & $\$ 645$ \\
\hline 6. Illinois & 36,935 & $\$ 609$ & 6. Florida & $1,158,238$ & $\$ 601$ \\
\hline 7. Michigan & 35,291 & $\$ 645$ & 7. Georgia & $1,099,350$ & $\$ 649$ \\
\hline 8. Florida & 28,832 & $\$ 601$ & 8. Ohio & 964,906 & $\$ 675$ \\
\hline 9. Louisiana & 25,739 & $\$ 666$ & 9. New Jersey & 817,601 & $\$ 531$ \\
\hline 10. Connecticut & 23,128 & $\$ 556$ & 10. Illinois & 737,472 & $\$ 609$ \\
\hline
\end{tabular}

SOURCE: BEA, Department of Labor, Kaiser Family Foundation, and authors' calculations.

a much higher purchasing power from $\$ 600$, such as Ohio, Louisiana, Georgia, and Michigan. To further explore this discrepancy, let's compare Ohio and New York, the states from the table where $\$ 600$ has the highest and lowest purchasing power, respectively. UI claimants in Ohio experience a 30 percent larger benefit from their UI supplement than claimants in New York. Take two workers who became eligible to receive UI benefits the first week of April ${ }^{4}$ and who will remain unemployed until July 31 . Over the course of these four months (18 weeks) the purchasing power of an Ohio claimant's total UI supplements ${ }^{5}$ would equal $\$ 12,150$ ( $\$ 675 \times 18$ ), while that of a New York claimant's would equal $\$ 9,324$ ( $\$ 518 \times 18$ ), a difference of $\$ 2,826$, which is over four times the nominal weekly amount of $\$ 600$.

The CARES act provides an extra $\$ 600$ per week in unemployment benefits, but the purchasing power of those dollars varies across states, raising the question of whether the equal distribution of $\$ 600$ across states is an equitable distribution.
This comparison raises the question of whether the equal distribution of the $\$ 600$ per week UI supplement is an equitable distribution across states. It raises the same question in response to the $\$ 1,200$ relief checks being distributed to many households across the United States. Certainly, anyone receiving financial aid will be better off than they would be without it; but the argument could be made that individuals who face higher prices for housing, food, and other essentials should receive higher UI supplements, particularly those who face a "double jeopardy" with regard to higher prices and more severe pandemic conditions.

However, setting the uniform $\$ 600$ per week supplement also has its advantages. First, the constant nominal amount of $\$ 600$ invokes the notion that this is a fair policy; all UI claimants are receiving the exact same amount. Additionally, having a flat supplement amount likely expedites the transfer of benefits to unemployed workers, many of whom need the aid as soon as possible. ${ }^{6}$ Moreover, the CARES Act is a large and detailed piece of legislation that needed to be passed quickly to provide relief to many factions of the economy; setting the UI supplement to a uniform amount may have mitigated debate surrounding the appropriate amount from region to region, enabling the act to be passed in short order. 


\section{ECONOMIC Synopses}

\section{Notes}

${ }^{1}$ RPPs are price indexes that reflect geographic price-level differences for a period of time in the United States. They reflect how much higher or lower prices in a state are compared with the national price level. RPP-adjusted dollar values reported here are in reference to the U.S. national price level. We use the most recent RPPs available, which reflect state-level price differences in 2017.

2 Data are from the Kaiser Family Foundation, updated April 23, 2020; https://www.kff.org/other/state-indicator/confirmed-covid-19-cases-and-deaths/?currentTimeframe $=0 \&$ sortModel $=\% 7 B \% 22$ colld $\% 22: \% 22$ Location $\% 22, \% 22$ sort $\% 22: \% 22$ asc $\% 22 \% 7 \mathrm{D}$.

3 Initial jobless claims data are from the Department of Labor, as of April 24, 2020.

4 The week ending April 4.

5 These calculations only reflect the total from the $\$ 600 \mathrm{UI}$ supplements claimants receive due to the CARES Act.

${ }^{6}$ Kurtzleben, Danielle. "What's In It For You? $\$ 1,200$ Checks, 13 Weeks Of Unemployment Payments And More." NPR, March 25, 2020;

https://www.npr.org/2020/03/25/821514231/whats-in-it-for-you-1-200-

checks-13-weeks-of-unemployment-payments-and-more. 